ISSN Cetak : 2087-0434

E-ISSN : :2599-0810

\title{
PALUGADA SEBAGAI KONSEP BISNIS UMKM DI MASA PANDEMI
}

\author{
Arum Arupi Kusnindar ${ }^{1)}$ Kohar $^{2)}$ \\ Fakultas Ekonomi dan Bisnis, Universitas Muhammadiyah Pringsewu \\ Email: arumkusnindar@gmail.com, koharlampung@umpri.ac.id, ${ }^{2)}$
}

\begin{abstract}
Abstrak
Kondisi pandemic dengan pembatasan sosial mengakibatkan masyarakat tidak bisa melakukan jual beli seperti yang biasa dilakukan. Pembatasan fisik atau social distancing membuat kita harus belajar cara baru dan memiliki ketrampilan baru dalam mengelola bisnis agar tetap dapat survive. Fleksibilitas, adaptasi dan kecepatan berubah menjadi kunci yang sangat penting untuk dapat bertahan. Ketahanan usaha pada saat ini, tidak hanya di tunjang oleh kemampuan modal, karena krisis yang terjadi belum dapat di prediksi kapan akan berakhir. Oleh klarena itu, fenomena yang diamati selama pandemic adalah munculnya retailer yang menggunakan internet sebagai media pemasaran dengan bisnis model yang berbeda. Jurnal ini mempunyai pendekatan teoritis dan metode wawancara terhadap fenomena model bisnis Palugada dalam era digital dan memberikan penekanan pada perbedaanya dengna konsep diversifikasi yang sudah dikenal sebelumnya. Serta bagaimana dampak konsep bisnis PaluGada terhadap pelaku usaha. Penelitian ini, memberi kesimpulan bahwa, terdapat ciri khusus dan variasi dalam konsep PaluGada yang sebelumnya tidak terdapat pada konsep diversifikasi. Sehingga, menjadi masukan bagi penelitian di masa depan terutama dalam perkembangan konsep diversifikasi dalam teori marketing.
\end{abstract}

\section{Kata Kunci: Diversifikasi, Digital Marketing, PaluGada}

\section{PENDAHULUAN}

Masyarakat di seluruh dunia telah berubah karena apa yang kita hadapi selama pandemi Covid-19. Tidak hanya telah mengubah fundamental ekonomi di semua negara namun secara perubahan secara sosial. Pembatasan sosial yang telah dan sedang dilakukan memberikan dampak ekonomi dan sosial yang luar biasa besar, angka pertumbuhan ekonomi yang minus, naiknya angka pengangguran, rendahnya daya beli masyarakat serta terhambatnya pasar sebagai sumber transaksi ekonomi di Indonesia, telah membawa kerugian yang sangat besar dan bahkan belum dapat di perhitungkan dengan akurat karena krisis pandemi belum juga berakhir. 
ISSN Cetak : 2087-0434

E-ISSN : :2599-0810

Krisis ekonomi yang terjadi saat ini berbeda dengan krisis yang terjadi pada tahun 1998 dan 2008. Pada tahun 1998, krisis ekonomi memberi dampak ekonomi paling besar di kota besar dan pada perusahaan perusahaan besar. Krisis bersumber tidak hanya dari fundamental ekonomi yang rapuh karena ketergantungan yang tinggi terhadap investasi dari luar negeri, tetapi juga dipengaruhi oleh lemahnya fundamental politik di dalam negeri. Krisis pada tahun 2008 lebih berimbas kepada sektor perbankan, karena bersumber dari permasalahan subprime mortagge yang terjadi di Amerika. Kedua krisis tersebut tidak memberi dampak besar terhadap UMKM. Saat perusahaan besar dan sektor perbankan mengalami permasalahan likuiditas, UMKM menjadi sektor yang menjadi penyelamat ekonomi.

Krisis ekonomi yang terjadi saat ini berdampak pada semua sektor dan skala usaha. Secara nasional, terdapat hampir 93,4\% UMKM terdampak pandemi. Sedangkan secara khusus survey yang dilakukan oleh Dinas Koperasi, Perindustrian dan Perdagangan di kabupaten Pringsewu, Lampung, terdapat 98\% UMKM terdampak. Ketika dilakukan survey lanjutan terhadap 804 UMKM yang terdampak, menunjukan penurunan omset sampai dengan $86 \%$ dengan sektor kuliner yang paling terdampak, diikuti sektor kreatif dan jasa. Secara lebih jelas hasil survey ditunjukan pada tabel dibawah ini:

Tabel 1. Data Dampak Pandemic Terhadap Omset UMKM Pringsewu

\begin{tabular}{|c|c|c|c|c|}
\hline Komoditas & $\begin{array}{l}\text { Rata-rata omset /minggu } \\
\text { sebelum covid }\end{array}$ & $\begin{array}{l}\text { Rat } \\
\text { sete }\end{array}$ & $\begin{array}{l}\text {-rata Omset /minggu } \\
\text { ah covid }\end{array}$ & $\%$ pe \\
\hline Kuliner & Rp. 954.153 & $\mathrm{Rp}$ & 131.181 & $86 \%$ \\
\hline Industri Kreatif & $\mathrm{Rp} \quad 291.667$ & $\mathrm{Rp}$ & 50.000 & $83 \%$ \\
\hline Jasa & $\mathrm{Rp} \quad 1.455 .556$ & $\mathrm{Rp}$ & 289.630 & $80 \%$ \\
\hline $\begin{array}{l}\text { Kerajinan dan } \\
\text { mebel }\end{array}$ & Rp 1.846 .296 & $\mathrm{Rp}$ & 484.074 & $74 \%$ \\
\hline $\begin{array}{l}\text { Industri } \\
\text { pengolahan }\end{array}$ & Rp 1.450 .000 & $\mathrm{Rp}$ & 417.500 & $71 \%$ \\
\hline Kerajinan kain & $\mathrm{Rp} \quad 1.289 .506$ & $\mathrm{Rp}$ & 426.235 & $67 \%$ \\
\hline $\begin{array}{l}\text { Batu Bata dan } \\
\text { genteng }\end{array}$ & $\begin{array}{ll}\mathrm{Rp} & 1.028 .571\end{array}$ & $\mathrm{Rp}$ & 342.857 & $67 \%$ \\
\hline $\begin{array}{l}\text { pertanian, } \\
\text { peternakan }\end{array}$ & Rp $\quad 905.000$ & $\mathrm{Rp}$ & 358.182 & $60 \%$ \\
\hline
\end{tabular}


ISSN Cetak : 2087-0434

E-ISSN : :2599-0810

\begin{tabular}{lcc}
\hline Kontruksi & $\mathrm{Rp}$ & 462.188 \\
\hline Kopi & $\mathrm{Rp}$ & 1.691 .111 \\
\hline Fashion & $\mathrm{Rp}$ & 1.162 .222 \\
\hline Perdagangan & $\mathrm{Rp}$ & 830.114 \\
\hline Perikanan & $\mathrm{Rp}$ & 1.116 .875 \\
\hline Rata - rata penurunan omset
\end{tabular}

\begin{tabular}{|c|c|}
\hline $\mathrm{Rp}$ & 186.250 \\
\hline $\mathrm{Rp}$ & 784.444 \\
\hline $\mathrm{Rp}$ & 668.056 \\
\hline $\mathrm{Rp}$ & 499.657 \\
\hline $\mathrm{Rp}$ & 756.563 \\
\hline
\end{tabular}

Sumber data: Dinas Koperindag Kabupaten Pringsewu, 2020

Pembatasan fisik atau social distancing membuat kita harus belajar cara baru dan memiliki ketrampilan baru dalam mengelola bisnis agar tetap dapat survive. Fleksibilitas, adaptasi dan kecepatan berubah menjadi kunci yang sangat penting untuk dapat bertahan. Ketahanan usaha pada saat ini, tidak dihanya di tunjang oleh kemampuan modal karena krisis yang terjadi belum dapat di prediksi kapan akan berakhir.

Beberapa perusahaan berusaha membuat stratgei dengan menurunkan biaya, melakukan efisiensi sampai pemutusan hubungan kerja dan menggunakan cash yang ada untuk bertahan. Strategi ini bisa berhasil jika perusahaan mempunyai cukup kas atau modal. Bagi UMKM, stratgei sangat sulit bertahan dengan mengandalkan uang kas yang ada, karena operasional UMKM sangat bergantung pada omset yang didapatkan setiap hari. Oleh karena itu, perubahan cara berbisnis bagi UMKM sangat penting agar mampu bertahan.

Dalam perubahan inilah dapat dilihat beberapa fenomena unik yang muncul pada para penggiat UMKM tidak saja fenomone digitalisasi pemasaran namun juga konsep strategi olshop dengan konsep PaluGada yang marak. Olshop adalah online shop dengan menjual banyak barang, dari makanan sampai dengan peralatan rumah tangga. Sebagian besar penjual dalam olshop adalah reseller dengan konsep seperti sebuah supermarket online. Mereka tidak punya produk sendiri tetapi menjual produk orang lain. Dengan konsep supermarket ini, mereka berusaha menjangkau banyak konsumen. Bahkan, istilah yang muncul pada toko online semacam ini di sebut "PaluGada" singkatan dari Apa loe mau gua ada. Dalam konsep ini, UMKM memanfaatkan teknologi digital (pada umumnya media sosial mereka) untuk menjual banyak barang. Keunikannya, barang yang mereka jual sangat beragam dan tidak sejenis, seperti pakaian dengan makanan. 
ISSN Cetak : 2087-0434

E-ISSN : :2599-0810

Dalam teori ekonomi, strategi olshop semacam ini dianggap sebagai strategi yang kurang focus, tidak terdifferensiasi dan sulit untuk memunculkan keunikan value perusahaan dan produk. Teori ekonomi cenderung menitikberatkan pada strategi differensiasi dan mengutamakan satu atau beberapa produk saja dibandingkan dengan banyak barang. Menjual banyak barang dianggap sebagai strategi yang high cost.

Berdasarkan uraian di atas, penelitian ini mencoba mengidentifikasi faktor apa saja yang membuat UMKM memilih menjual banyak barang ketimbang focus pada beberapa barang saja.

Porter (1985) dalam Saren \& baker (2012) memperkenalkan 3 generik strategi pemasaran yaitu, strategi Keunggulan Biaya atau Cost Leadership, strategi Pembedaan Produk atau Differentiation, dan strategi Focus. Strategi Biaya Rendah (cost leadership) menitik beratkan pada produksi produk yang standar (sama dalam segala aspek) dengan biaya per unit yang sangat rendah. Produk ini (barang maupun jasa) pada umumnya diperuntukan pada konsumen yang relatif mudah dipengaruhi oleh pergeseran harga (price sensitive) atau memakai harga sebagai faktor penentu untuk pengambilan keputusan pembelian. Dari sisi perilaku pelanggan, strategi jenis ini amat sesuai dengan kebutuhan pelanggan yang termasuk dalam kategori perilaku low-involvement, pada kategori ini, konsumen kurang peduli pada merek, kurang memperhatikan pembedaan produk, atau jika terdapat sejumlah besar konsumen memiliki kekuatan tawar-menawar yang signifikan.

Pada pasar komoditi, strategi ini mampu membuat perusahaan menjadi pemimpin pasar (market leader). Seorang pemimpin pasar dapat menentukan harga dan mendapat keuntungan pasar yang tinggi dibandingkan dengan pesaing yang lain. Keuntungan ini berasal dari keefektifan biaya (cost effectiveness) dan pemanfaatan skala ekonomi (economies of scale), pemanfaatan teknologi, optimasi kapasitas utilitas, dan akses yang luas pada saluran bahan baku atau saluran distribusi.

Strategi Pembedaan Produk (differentiation), menitikberatkan pada kemampuan perusahaan menemukan keunikan produk mereka dibandingkan dengan produk produk lain di pasar. Keunikan produk (barang atau jasa) ini memungkinkan suatu perusahaan untuk mendapatkan perhatian dari konsumen. Differensiasi produk dapat dilakukan pada sifat dan atribut fisik suatu produk (rasa, bentuk, kemasan dan 
ISSN Cetak : 2087-0434

E-ISSN : :2599-0810

sebagainya) atau pengalaman kepuasan konsumen (secara nyata maupun psikologis) yang didapatkan karena memakai produk tersebut (pada umumnya pada produk produk kecantikan, kesehatan dan jasa). Keunikan lain bisa di dapatkan dari berbagai kemudahan perawatan, features tambahan, fleksibilitas, kenyamanan dan berbagai hal lainnya yang sulit ditiru pesaing. Strategi jenis ini biasa ditujukan kepada para konsumen potensial yang relatif tidak mengutamakan harga dalam pengambilan keputusannya (price insensitive).

Strategi fokus, menitikberatkan hanya pada satu atau beberapa produk saja untuk membangun keunggulan bersaing dalam suatu segmen pasar. Strategi ini sangat spesifik dan ditujukan untuk memenuhi kebutuhan konsumen yang jumlahnya relatif kecil namun tidak dipengaruhi oleh harga dalam pengambilan keputusan pembelian. Pada perusahaan skala menengah dan besar - , strategi fokus diintegrasikan dengan salah satu dari dua strategi lainnya, yaitu strategi biaya rendah atau strategi pembedaan produk. Untuk mampu memanfaatkan ceruk pasar atau "niche market" (segmen khusus dalam suatu pasar tertentu).

Ketiga strategi di atas digambarkan dalam bentuk sebagai berikut:

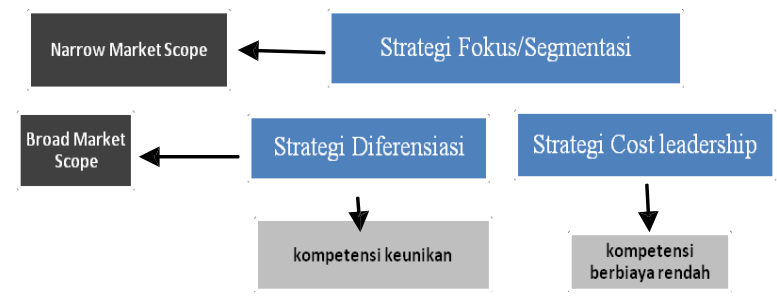

\section{Gambar 1. Strategi Marketing}

Fenomena olshop dengan konsep "PaluGada" yang saat ini marak dilakukan oleh UMKM sulit untuk dikategorikan pada salah satu strategi di atas, karena ciri-ciri pada konsep ini tidak mampu merujuk pada salah satu dari ketiga konsep pemasaran $\begin{array}{llll}\text { yang sudah kenal } & \text { kita }\end{array}$ 
ISSN Cetak : :2087-0434

E-ISSN : : 2599-0810

PaluGada adalah sebuah istilah yang mulai populer dalam e-commerce di Indonesia pada tahun 2015, terutama dalam pasar daring/digital. PaluGada digunakan untuk menyebut model usaha yang tidak membatasi penawaran pada satu jenis barang atau jasa. Model bisnis PaluGada mengamati apa saja permintaan di pasar dan mengambil bermacam kesempatan bisnis dari sana. Sehingga, ada seseorang yang menjual peralatan kosmetik sampai dengan makanan kecil bahkan furniture. Model bisnis ini bertentangan dengan konsep focus atau segmentasi dan konsep differensiasi, namun juga bukan strategi cost leadership. Konsep Palugada lebih dekat kepada konsep diversifikasi/keberagaman dengan beberapa cirri khusus yang membedakan diversifikasi yang dilakukan oleh pada pelaku Konsep PaluGada dan konsep diversigikasi yang diperkenalkan oleh Porter.

UMKM yang melakukan pemasaran digital dengan konsep Palugada mempunyai cirri cirri sebagai berikut:

1. Mudah. Tidak perlu mengkhususkan diri terhadap suatu hal, dengan banyaknya barang yang di jual, maka banyak yang bisa di gunakan sebagai alat pemasaran.

2. Berbiaya rendah. Pada umumnya, UMKM dengan konsep bisnis ini dan bergerak pada platform digital memakai konsep PO (purchase order), mereka meminta konsumen pesan terlebih dahulu dan mereka baru akan membeli dari produsen yang bersangkutan. Sehingga, mereka tidak memerlukan stok barang dalam jumlah besar.

3. Konsep ini merupakan campuran dari tipe reseller dan dropshipper. Marketer bisa menjual barang hanya dari foto dan proses pembelian oleh konsumen dilakukan melalu pemesanan terlebih dahulu seperti halnya dropshipper, bedanya mereka harus mengeluarkan uang terlebih dahulu untuk mendatangkan barang yang dipesan konsumen. Sedangkan dropshipper tidak perlu mengeluarkan uang terlebih dahulu, pembelian langsung ditujukan kepada produsen, dan pelaku dropshipper mendapatkan margin atau komisi. Namun, margin yang didapatkan lebih kecil dari reseller. 
ISSN Cetak : 2087-0434

E-ISSN : : 2599-0810

4. Barang yang di tawarkan beragam dan tidak selalu berada dalam kategori yang sama. Harapan marketer adalah, semakin banyak jenis barang yang ditawarkan, semakin banyak kemungkinan orang yang akan membeli

5. Berorientasi pada kebutuhan pelanggan atau pasar.

6. Berpotensi mengembangkan perusahaan sehingga tidak hanya terpaku pada satu jenis layanan yang telah dikuasai saja

Dalam Strategi Diversifikasi, Kotler (2008) dalam Saren \& baker (2010) menyatakan konsep diversifikasi produk merupakan salah satu cara untuk meningkatkan kinerja bisnis yang ada dengan jalan mengidentifikasi peluang untuk menambah bisnis menarik yang tidak berkaitan dengan bisnis perusahaan saat ini.

Terdapat 3 bentuk strategi diversifikasi yaitu;

1. Diversifikasi konsentris, yaitu strategi penambahan produk baru yang masih ada kaitannya dalam hal kesamaan teknologi, fasilitas bersama, atau jaringan pemasaran yang sama dengan produk yang ada saat ini

2. Diversifikasi horizontal, merupakan strategi pengadaan produk baru yang tidak berkaitan dengan produk dan pelanggan yang ada saat ini. Yang didasarkan pada tingkat loyalitas pelanggan terhadap merk atau brand perusahaan,

3. Diversifikasi konglomerasi, yaitu strategi penambahan produk baru yang dipasarkan di pasar baru yang tidak berkaitan dengan produk dan pasar saat ini yang ada saat ini.

\section{METODE PENELITIAN}

Penelitian ini merupakan penelitian kualitatif dengan menggunakan pendekatan intepretatif. Data yang dipakai adalah data primer berupa wawancara terhadap satu pelaku UMKM yang memakai konsep PaluGada dan data sekunder yang berasal dari buku-buku dan jurnal yang relevan. Wawancara dilakukan secara terstruktur dengan pertanyaan yang di konstruksikan dari jurnal terkini mengenai pemilihan konsep bisnis dalam era digital untuk small medium enterprise. 
ISSN Cetak : :2087-0434

E-ISSN : : 2599-0810

Wawancara dilakukan dengan Ibu Eka pemilik UMKM dengan label Dapur Mbak EKA. Dapur Qtree sudah mendapat ijin PIRT untuk produk cemilan akar kelapa dan brownies, selain itu pemilik usaha ini juga sangat kreatif dalam membuat dan menjajakan kue dan jajanan tradisional Lampung. Promosi dilakukan melalui media sosial yang dimiliki Ibu Eka yaitu melalui aplikasi chatting/whatsapp, facebook dan IG. Namun, mulai bulan April 2020, produk yang di tawarkan mulai berubah. Tidak hanya mempromosikan hasil olahannya sendiri, Ibu Eka juga mempromosikan dan menjual peralatan dapur, furniture dan fashion. Oleh karena itu, pemilik dapur Qtree menjadi responden yang dipilih dalam penelitian ini. Tidak saja sudah memanfaatkan media sosial dalam melakukan penjualan, namun juga memiliki konsep PaluGada. PIRT untuk produk cemilan akar kelapa, selain itu pemilik usaha ini juga sangat kreatif dalam membuat dan menjajakan kue dan jajanan tradisional Lampung. Promosi dilakukan melalui media sosial yang dimiliki Ibu eka yaitu melalui aplikasi chatting/whatsapp, facebook dan IG. Namun, mulai bulan April 2020, produk yang di tawarkan mulai berubah. Tidak hanya mempromosikan hasil olahannya sendiri, Ibu Eka juga mempromosikan dan menjual peralatan dapur, furniture dan fashion. Oleh karena itu, pemilik dapur Mbak Eka menjadi responden yang dipilih dalam penelitian ini. Tidak saja sudah memanfaatkan media sosial dalam melakukan penjualan namun juga memiliki konsep PaluGada

\section{HASIL DAN PEMBAHASAN}

Hasil wawancara, di tunjukan dalam tabel di bawah ini:

Tabel 2. Hasil Wawancara

\begin{tabular}{|c|c|}
\hline Pertanyaan & Tanggapan Responden \\
\hline $\begin{array}{l}\text { Bagaimana ibu menjalankan } \\
\text { usaha,? }\end{array}$ & $\begin{array}{l}\text { Menjalankan usaha dari rumah, tanpa memiliki warung } \\
\text { atau menyewa ruko. }\end{array}$ \\
\hline $\begin{array}{l}\text { Bagaimana cara ibu } \\
\text { mempromosikan produk? }\end{array}$ & $\begin{array}{l}\text { Produk dipromosikan melalui media social yaitu WA, } \\
\text { FB dan IG. Saya tidak hanya memakai akun saya } \\
\text { sendiri, tetapi juga akun anak saya }\end{array}$ \\
\hline $\begin{array}{l}\text { Berapa jenis produk yang } \\
\text { Ibu jual dan apakah produk } \\
\text { tersebut hasil produksi ibu } \\
\text { sendiri? }\end{array}$ & $\begin{array}{l}\text { Saya menjual lebih dari } 50 \text { produk, dari produk } \\
\text { makanan olahan saya sendiri, peralatan dapur dari } \\
\text { produsen di Jakarta sebagai dropshipper dan pakaian } \\
\text { dari }\end{array}$ \\
\hline
\end{tabular}


ISSN Cetak : 2087-0434

E-ISSN : :2599-0810

Mengapa memilih promosi lewat media social dan bukan menyewa ruko dan menjual hanya produk unggulan (makanan) olah ibu?
Berjualan lewat medsos, sangat murah, hanya perlu kuota, tidak perlu sewa ruangan/ruko, saya hanya panggil karyawan bantu kalau pesanan banyak. Anak saya juga bisa membantu menjual melalui IG mereka.
Apakah ada perbedaan omset penjualan saat ibu menjual hanya produk makanan dan saat ibu menjual banyak produk selain makanan?
Omset naik pesat. Apalagi peralatan dapur dan rumah tangga. Makanan juga naik pesat, dari omset ketika hanya produk makanan sekitar $4-5$ juta per bulanmenjadi $10-12$ juta per bulan. Kenalan saya bertambah, Karena pelanggan yang membeli kadang mempromosikan ke rekan mereka

Saya melihat kebutuhan pasar. Saya sering ditanya oleh teman-teman, dimana beli peralatan dapur, atau pot bunga, serta dimana membeli kerudung dan gamis yang murah. Oleh ,karena itu, saya menilai kalau saya jualan produk itu pasti ada peminatnya.

$\overline{\text { Apakah ibu tidak takut jika Saya tidak takut, malah dengan menjual banyak produk }}$ pelanggan lebih mengenal saya juiga menambah pelanggan yang bisa saya produk ibu yang lain tawarkan produk makanan olahan saya. ketimbang produk makanan yang menjadi cirri khas ibu?

The retal format diversification on retail's financial performance. (France \& Lim, 2017)

\section{Kemampuan apa yang harus Saya harus belajar cara berpromosi dengan baik, ibu tingkatkan untuk ke membuat foto yang bagus agar bisa di tampilkan di depannya? medsos lebih menarik seperti produk dari perusahaan besar.}

\section{Sumber: Data Primer diolah}

Hasil wawancara di atas menegaskan bahwa konsep PaluGada yang di adopsi oleh UMKM mempunyai ciri-ciri :

1. Mereka tidak mengikuti format baku jenis diversifikasi yang ada yaitu diversifikasi konglomerasi, karena segmen pasarnya sebenarnya masih sama, karena barang yang dijual tidak memiliki kesamaan teknologi/value, dan bukan pula diversifikasi horizontal karena produk yang dijual terdiri dari brand yang bermacam macam dan konsumen tidak loyal terhadap brand tertentu.

2. Tujuan utama dari konsep PaluGada adalah mendapatkan sebanyak mungkin konsumen/pembeli.

3. Tujuan lain terutama dengan digital marketing adalah, faktor biaya. Dengan berjualan secara daring mereka tidak perlu sewa tempat dan mereka juga tidak 
ISSN Cetak : 2087-0434

E-ISSN : :2599-0810

perlu stock barang dalam jumlah besar.

Diversifikasi dengan konsep PaluGada dengan kondisi pandemi dan pelaku usaha kecil, konsep diversifikasi mengalami beberapa perbedaan dengan konsep yang ada.Konsep PaluGada mempunyai ciri unik yaitu:

1. Bersifat local and sustainable

Pelaku usaha melihat kesempatan pada pasar local. Mereka berusaha memenuhi kebutuhan pada segmen tersebut, Karena kebutuhan beragam, sehingga produk yang mereka tawarkan juga beragam

2. Melakukan komunikasi efektif dan intensif secara langsung kepada pelanggan, sehingga konsep marketing hampir mengarah kepada digital direct marketing. Berbeda dengan konsep diversifikasi perusahaan besar, mereka tidak melakukan direct marketing karena akan terlalu mahal

\section{Small Format shop}

Mereka melakukan mixed antara vertical dan horizontal diversification dengan tetap mempertahankan format toko kecil berbiaya operasional yang rendah.

\section{KESIMPULAN}

Model bisnis Palugada secara digital menimbulkan variasi dalam konsep diversifikasi. Diversifikasi yang dilakukan oleh pelaku usaha mikro, kecil dan menengah merupakan campuran dari diversifikasi vertical dan horizontal. Mereka juga tidak mempunyai pertimbangan risiko seperti pada umumnya perusahan besar melakukan diversifikasi produk. Tetapi mereka mempunyai konsep ekspansi usaha dengan cara mendapatkan pelanggan sebanyak mungkin.

Cara ini terbukti membantu UMKM tetap bertahan dimasa sulit selama pandemi dan pembatasan sosial. Konsep diversifikasi secara daring dengan mempertahankan biaya operasional serendah mungkin mampu meningkatkan omset penjualan dan menambah pelanggan/konsumen. Mereka bahkan mampu memanfaatkan pelanggan-pelanggan baru untuk menjadi pelanggan bagi produk asli/utama

mereka. 
ISSN Cetak : 2087-0434

E-ISSN : :2599-0810

Konsep bisnis ini, bisa diteliti secara lebih mendalam karena terdapat potensi pengayaan teori diversifikasi khususnya pada pelaku usaha mikro, kecil dan menengah pada masa pandemic.

\section{REFERENSI}

France, stephen \& Jeremy Lim., "The impact of retail format diversification on relailer's financial performance". Jurnal of the academy Marketing Science". Vol 46 Page 147 - 167. 2017

Gielens, Katrijn \& Steenkamp., "Branding in the era of digital (dis) intermediation". Jurnal of Research on Marketing". Vol 36 Page 367 - 384. North California University. 2019

Verhoef, C.Peter \& Bijmol. HA., "Marketing perspective on digital business model: A Framework and overview of the special issue". Jurnal of Research on Marketing". Vol 36 Page 341 - 349 Groningen University, Neterhlands. 2019

Saren, Michael \& Baker, Michael. "Marketing Theory; a student text". Sage

Publication Inc.. California. 2010 